\title{
Transfer in L3 Acquisition: Is it Holistic or Property-Based?
}

\author{
Karima Ben Abbes \\ Foundation Program \\ Qatar University \\ Doha-Qatar
}

\begin{abstract}
This study investigated the predictions of current L3 models in the learning of three morpho-syntactic properties (i) gender (ii) number concord (iii) and articles by two groups of beginner L3 French learners: L1 Spanish-L2 English and L1 Turkish-L2 English. Using quantitative and qualitative instruments, results of the Spanish group have shown support for holistic transfer based on typological proximity (the TPM, Rothman, 2011, 2013, 2015), whereas the Turkish results seem to support transfer on a property-by-property basis (the LPM, Westergaard, et al., 2016). This study concludes that when L1 or L2 is clearly typologically similar to the L3 (lexically, syntactically, morphologically, and is also of the same family origin of the L3), the parser would transfer all the properties of that language to the L3 grammar on a holistic basis. However, if L1 and L2 are both typologically distant from L3, though one of them might be lexically much closer to the L3 than the other, transfer is possible from both languages on a property-by-property basis.
\end{abstract}

Keywords: L3, transfer, Gender, Number, Articles, holistic transfer, property-by-property basis

\section{Introduction: Current L3 models}

L3 studies have proposed a variety of models in an attempt to predict the source (s) of transfer at the initial state of third language acquisition (L3A). However, the majority of these models generally fit into one of two categories: wholesale transfer or partial transfer models (Brown, 2020; Puig-Mayenco et al., 2018).

\subsection{Wholesale Transfer Models}

Wholesale transfer models, as their name indicates, predict one language to be the predominant source of transfer, whereas the non-transferred language does not contribute any features to the L3 at the initial stage of acquisition. However, models under this category differ with regard to which factors determine whether the L1 or the L2 serves as the source of transfer. Three models fall under this category, briefly reviewed in this section.

\section{The L1 Privilege Model}

This model argues that L1 holds a privileged status as the speaker's native language and, therefore, serves as the predominant source of transfer for syntactic features in early L3A. To best of my knowledge, this model has only been supported by the studies of Hermas (2010, 2014a, 2014b).

\section{The L2 Status Factor}

The L2 Status Factor (Bardel and Falk, 2007; Falk and Bardel, 2011; Falk 2017; Falk \& Lindqvist 2019; Jaensch, 2009a; Leung, 2005b) claims that increased metalinguistic awareness of L2 syntactic features as well as similarities in the acquisition experience, such as learning both the L2 and the L3 in adulthood, make the L2 become the main source of transfer at the initial state of L3A. Hence, the syntactic properties of the L3 grammar at the early stages of L3A are more likely to be affected by L2 syntactic features than by those of the L1.

\section{The Typological Primacy Model (TPM)}

The Typological Primacy Model (TPM: Rothman, 2011, 2013, 2015) rejects the notion of a privileged status either for the L1 or the L2. In contrast, it claims that (psycho) typological similarity between the L3 and L1/L2, rather than order of acquisition, is the driving variable for the selection of L1 or L2 as the source of transfer at the initial stage of L3A. The selection of which language to transfer holistically (L1 or L2) is based on an implicational hierarchy: Lexicon $\rightarrow$ Phonology/Phonotactics $\rightarrow$ Functional Morphology $\rightarrow$ Syntax. Rothman argues that lexical similarity is the first trigger that can help the parser identify whether a language is typologically similar to the L3 or not. The parser cannot identify morphological or syntactic similarities early on in L3A for both require advanced proficiency level in the L3. Hence, once the parser identifies which language is lexically more similar to the L3 than the other one, it will transfer all of the properties of that language to the L3 grammar on a wholesale transfer basis. 


\subsection{Partial Transfer Models}

Unlike the whole transfer models, which claim that one language is transferred in its entirety to the exclusion of any other previously learned language(s), partial transfer models propose that all previously learned languages could contribute to the development of L3 grammar in its early stage of acquisition. That implies that the parser does not necessarily have to transfer the grammatical system of L1 or L2 all at once. Instead, individual grammatical properties of L1 and L2 could be both transferred as needed. Three models fall under this category, briefly reviewed in this section.

\section{The Cumulative Enhancement Model (CEM)}

The CEM (Flynn et al., 2004; Berkes \& Flynn, 2012) proposes that transfer can be either facilitative or does not occur at all. In particular, the CEM argues that all learned languages (L1 and L2) can either positively enhance subsequent language acquisition or have no effect. This means that non-facilitative transfer from previously acquired languages does not occur.

\section{The Linguistic Proximity Model}

The Linguistic Proximity Model (LPM: Westergaard, et al., 2016) argues that language acquisition is cumulative and that learners have access to all previously acquired languages. That means none of the linguistic systems of any of the previously learned languages is blocked at any stage of the acquisition process. In addition, it advocates facilitative transfer based on structural similarity and on a property-by-property basis (contra the holistic predictions of the TPM). The LPM also claims that non-facilitative transfer is possible (contra the CEM), but it is the result of learners incorrectly assuming that a linguistic property is shared between a previously acquired language and the L3.

\section{The Scalpel Model}

The Scalpel Model (Slabakova, 2016) states that (i) 'wholesale' transfer of one of the previously acquired languages does not happen at the initial stages of acquisition because it is not necessary. Transfer can be from the L1 or the L2 or both, and it happens on a property-by-property basis (contra the TPM) (ii) transfer is both facilitative and non-facilitative (contra the CEM), (iii) typological proximity is not the only variable that triggers transfer in L3A, other variables such as structural linguistic complexity, misleading input or lack of clear unambiguous evidence for some property, construction frequency in the target L3, and prevalent language activation or use are factors that can help explain the differential learnability of properties across different groups of L3 learners.

\section{The study}

\subsection{Aims of the study}

The present study set out to test the predictions of the L3 models reviewed above with regard to the source of transfer at the initial stage of L3 French acquisition by two groups of participants: group 1: L1 Spanish-L2 EnglishL3 French and group 2: L1 Turkish-L2 English-L3 French. Three morpho-syntactic properties are under investigation: gender (assignment and concord), number concord, and article choice (definite versus indefinite). Accordingly, the next sub-section is divided as follows: (i) a theoretical description of the properties tested and their distributions across the tested languages, (ii) research questions (iii) a description of the experimental participants in this study, (iv) the experimental tests used and (v) their results.

\subsection{Properties tested and Cross-linguistic differences}

\subsubsection{Gender assignment and concord}

In both French and Spanish, nouns $(\mathrm{N})$ are assigned to one of two gender classes: masculine or feminine. This has consequences for the form that accompanying determiners (Ds) and adjectives (Adjs) take (gender concord). The following examples illustrate these consequences:
French le livre vert
the-masc book-masc green-masc 'the green book'
la porte verte
the-fem door-fem green-fem 'the green door'

Spanish el sombrero negro 
the-masc hat-masc black-masc 'The black hat'

la chaqueta negra

the-fem jacket-fem black-fem 'the black jacket'

Neither English nor Turkish divides Ns by grammatical gender class and there is no gender concord with their Ds and Adjs.

\subsubsection{Number concord}

Ns inflect for number in French, English, Spanish and Turkish, although in French this typically has no phonetic reflex. However, only French and Spanish have number concord between the N, Ds and Adjs (but in French, concord on Adjs typically has no phonetic reflex):

$\begin{array}{lll}\text { French: } & \text { les livres verts } \\ & \text { the-pl book-pl green-pl }\end{array}$

Spanish: los sombreros negros

English: the black hat/the black hats

Turkish: güzel araba / güzel arabalar 'the beautiful car/the beautiful cars' the-pl hat-pl black-pl

'the green books'

'the black hats'

beautiful car-sing/beautiful car-pl

\subsubsection{Articles}

English, French, and Spanish have article systems that encode definiteness (definite versus indefinite articles) as follows: (English the/a, French le/le un/une, Spanish el/la un/una). Some languages, on the contrary, appear to have article systems that encode specificity: specific versus non-specific, for example, Samoan (Ionin, Zubizarreta and Philippov, 2009). There has been some debate about whether Turkish has an article system or not or whether it encodes specificity and/or definiteness (Underhill, 1976; Kornfilt, 1997). That is mainly raised due to the existence of the numeral ('bir'/one) and some demonstratives ( $b u$ 'this', $o / s ̧ u$ 'that') which are treated as being encoding definiteness or specificity, respectively. However, given that bir, bu and o/şu are used in certain contexts while in others they are not, they cannot be treated as articles, simply because articles are known for their compulsory presence. Thus, as the focus of this study is on the appropriate use of articles, and as Turkish does not seem to have articles (at least not in the way English, French, and Spanish do), this work will adopt the assumption that Turkish does not have an article system (Yilmaz, 2006).

Table 1: Summary of property distribution by language

\begin{tabular}{|l|l|l|l|l|}
\hline \multirow{2}{*}{ Feature/property } & \multicolumn{2}{l}{ L1 } & L2 & L3 \\
\cline { 2 - 5 } & Spanish & Turkish & English & French \\
\hline Gender assignment and concord on Ds/Adjs & $\sqrt{ }$ & X & X & $\sqrt{ }$ \\
\hline Plural marking on N & $\sqrt{ }$ & $\sqrt{ }$ & $\sqrt{ }$ & $\sqrt{ }$ \\
\hline Plural marking (Number concord) on Ds/Adjs & $\sqrt{ }$ & $X$ & $X$ & $\sqrt{ }$ \\
\hline Definite and indefinite articles & $\sqrt{ }$ & $X$ & $\sqrt{ }$ & $\sqrt{ }$ \\
\hline
\end{tabular}

$\sqrt{ }$ : The property is present. $X$ : The property is absent.

\subsection{Research questions}

French and Spanish are not only of the same family origin (both Romance languages) and typologically similar but are also structurally alike with regard to the properties tested. English and Turkish, on the contrary, are structurally different from French, except for plural marking on Ns (both English and Turkish), and definiteness (only English).

In light of the above cross-linguistic distribution, the present study aims to answer two questions:

- Does transfer come from L1, L2, or both in early L3 French acquisition?

- If typological proximity is the driving variable for transfer, does it happen holistically (the TPM) or on a property-by-property basis (The Scalpel Model and the LPM)

To answer the second question, it is important to identify which language is lexically closer to L3 French. This is because Rothman $(2013,2015)$ argues that lexical similarity is the first criterion that attracts the parser to identify which language is typologically closer to the L3. Once that language is identified, the parser would transfer all of 
its properties to the L3 grammar on a wholesale basis. Hence, it is worth identifying which language (the L1 or the L2) is lexically closer to the L3 French for the two experimental groups of this study.

Two measurements are used to identify the lexical similarity between the languages in questions. In the case of L1 Spanish $\rightarrow \mathrm{L} 2$ English $\rightarrow \mathrm{L} 3$ French group, the statistics collected from Ethnologue: Languages of the world ${ }^{l}$ reveal that lexical similarity between Spanish and French approximately represents about 75\% while English-French lexical similarity is only around $27 \%$. Hence, Spanish is lexically more similar to French than English to French.

In the case of L1 Turkish $\rightarrow$ L2 English $\rightarrow$ L3 French group, the statistics are collected from the Turkish Language Association (original work of New \& Pallier, 2001) ${ }^{2}$, which states that lexical similarity between Turkish and French represents approximately $4.76 \%$. Hence, English is lexically more similar to French than Turkish to French.

Table 2: Lexical similarity by Language (L1, L2, L3)

The Spanish Group

\begin{tabular}{|l|l|}
\hline Languages & L3 French \\
\hline L1 Spanish & $75 \%$ \\
\hline L2 English & $27 \%$ \\
\hline
\end{tabular}

The Turkish group

\begin{tabular}{|l|l|}
\hline Languages & L3 French \\
\hline L1 Turkish & $4.76 \%$ \\
\hline L2 English & $27 \%$ \\
\hline
\end{tabular}

\subsection{Participants}

16 Turkish native speakers (mean age $=25.5$, age range $=19-34)$, 22 Spanish native speakers $($ mean age $=24.1$, age range $=19-38$ ) and a control group of 10 French native speakers from different parts of France (mean age $=$ 21.2, age range $=19-24)$ participated in the study. All participants were (male and female) students at the University of Essex at the time of testing and were recruited from a variety of disciplines. To ensure that participants were beginners only in French and had only learned one L2 - English - before the study, a bio-data questionnaire was used to eliminate those who had had more than two years of exposure to French and/or who had already learned a third language. Finally, only participants who were classified as beginners by the online Oxford French Placement Test were selected for the study ${ }^{3}$. The participants selected were further subdivided following an Oxford English Placement Test (OEPT) into two sub-groups 'lower- intermediate' and 'advanced' based on their proficiency in L2 English, as shown in table $3^{4}$.

Table 3: Groups divided by $L 1$ and $L 2$ proficiency

\begin{tabular}{|l|l|l|l|}
\hline L2 prof & & L1 French (control group) \\
\hline Low Intermediate & L1 Spanish & L1 Turkish & \\
\hline Advanced & 9 & 6 & \multirow{2}{*}{10} \\
\hline Total & 13 & 10 & \\
\hline
\end{tabular}

\subsection{Method}

This study relied on a 'mixed method' methodology, consisting of quantitative instruments (a multiple-choice translation, MCT test and an acceptability sentence correction, ASC test) and a qualitative instrument, which is a questionnaire to elicit information about the participants' perceptions of typological similarity between their L1/L2 and L3.

\footnotetext{
${ }^{1}$ Ethnologue: Languages of the World is a web-based publication that contains statistics for about 7,457 languages. Ethnologue provides information on the number of speakers, location, dialects, linguistic affiliations and some other relevant features related to this language. This site is well respected and widely used by many linguists.

2 According to the Turkish Language Association, the total Turkish words are 104,481, of which about $86 \%$ are Turkish and $14 \%$ are of foreign origin (words borrowed from French are about 4.974 i.e. $4.76 \%$ ).

${ }^{3}$ The online Oxford French Placement Test (OFPT) is an online French placement test, which is freely accessible through the website of Oxford Language Centre, Oxford University. (http://www.lang.ox.ac.uk/courses/tst_placement_french.html). Normally, there are two levels of beginners: complete beginners who score (1-3) and false beginners who score (4-10); however, for the purpose of this study, the two levels were merged and consequently, any participant who scores (1-10) is a beginner in this study.

${ }^{4}$ The oxford English Placement tests consisted of 60 multiple-choice questions. There was no time limit for this test but all participants finished the test within 30 to 50 minutes.
} 


\subsubsection{Multiple Choice Translation Test (MCT)}

The MCT test aimed to elicit information about participants' acquisition of gender assignment/concord, number concord, and article choice in L3 French. A total of 38 sentences were used: 12 sentences testing gender, six testing Number concord, and 12 testing article choice and eight distracters. Participants were given a sentence in English followed by four sentences which served as possible translations in French. They were told to tick the option they found grammatically acceptable in French.

\section{- Gender:}

Four contexts were tested in this test: [Masc Def ]/ [Masc Indef]/ [Fem Def]/ [Fem Indef]. For each context, there were four sentences, each dealing with one case, as shown by the example below:

She is wearing a white dress.
a. Elle porte une robe blanc. Wrong gender concord on Adj
b. Elle porte une robe blanche. Correct option
c. Elle porte un robe blanc. Wrong gender assignment, consistent concord
$d$. Elle porte un robe blanche. Wrong gender concord on $D$

\section{- Number}

All nouns tested were [pl. Masc Def ] or [pl. Masc Indef]. There were eight tested sentences in total, each dealing with one case, as shown by the example below:

They love the green curtains.
a. Ils aiment les rideaux verts.
Correct option
b. Ils aiment le rideaux vert.
Wrong number concord on both $D$ and Adj
c. Ils aiment le rideaux verts.
Wrong number concord on D
d. Ils aiment les rideaux vert.
Wrong number concord on Adj

\section{- Article choice}

Sentences testing article choice were distributed across two contexts: [+Def] and [-Def]. For each context, there were eight tested sentences, each having four possible options in French (distributed randomly in the test). Here is an illustrative example ${ }^{5}$ :

[+Def]: The police are looking for the burglar who broke into the professor's house. They have no idea who it might be.

They are looking for the burglar.
a. Ils cherchent le voleur.
Correct option
$b$. Ils cherchent un voleur.
Substitution error (Indef for Def)
c. Ils cherchent voleur.
The use of zero $(\varnothing)$ article (article omission error)
d. Ils cherchent du voleur. Wrong use of article: The use of partitive article (du= 'some' instead of 'le')

\subsubsection{Acceptability Sentence Correction (ASC) Test}

This test asked participants to identify whether a sentence was grammatical or not in French. If a sentence was identified as ungrammatical, participants were asked to correct it. There were 16 sentences testing gender, eight sentences testing number concord, 16 testing article choice, and 12 served as distracters.

\section{- Gender}

Four contexts were tested in this test: [Masc Def ]/ [Masc Indef]/ [Fem Def]/ [Fem Indef]. For each context, there were four sentences, each dealing with one case (as in the MCT test above):
a. Correct option
b. Wrong gender assignment, consistent concord
c. Wrong gender concord on Adj
d. Wrong gender concord on $D$

Participants were asked to correct the sentences in cases (b-c-d) but write 'acceptable' in case (a).

\section{- Number}

Two contexts were tested in this test: [pl. Masc Def ] and [pl. Masc Indef]. For each context, there were four sentences, each dealing with one case. The sentences used in this test paralleled those used in the MCT test:

\section{a. Correct option}

${ }^{5}$ In two other studies, there were four contexts [+Def, + Spec], [-Def, + Spec], [+Def, - Spec] and [-Def, - Spec] for both tests, the MCT and the ASC tests. However, for the purpose of this study, we are just reporting results on articles in two contexts [+Def] and [-Def], refer to Ben Abbes (2016) and Ben Abbes (2017) for further details. 
b. Wrong number concord on both D and Adj

c. Wrong number concord on D

d. Wrong number concord on Adj

\section{- Article choice}

Four contexts were used, divided by definiteness and specificity: [+Def, + Spec], [+Def, - Spec], [-Def, + Spec] and [-Def, -Spec]. Each of the four contexts was realized by four sentences, each dealing with four cases (as in the MCT test).
a. Correct option
b. Substitution Error (Deffor Indef or vice versa)
c. The use of zero $(\emptyset)$ article (article omission error)
d. Wrong use of article: The use of partitive article ('du'=some instead of 'the' in Def contexts, or ' $a$ ' in Indef contexts).

\subsubsection{Qualitative questionnaire}

In addition to the two quantitative experimental tests described above, this study used a qualitative instrument, which was a questionnaire with closed-ended and open-ended questions. This questionnaire aimed to explicitly ask participants about their perceptions of holistic and property-based similarity between the L1/L2 and the L3. Closed questions were of three types: questions asking participants to rate the similarity/difference level between their L1/L2 and L3 in general, questions asking to rate the difficulty level of the properties tested in L3 French and one question asking whether L2 English was helpful or not when learning L3 French. Illustrating examples are presented below:

Samples of closed-questions on similarity/differences between L1/L2 and L3 in general:

How similar/different the following pairs of languages?

a) French and Spanish

Very similar Not similar at all

b) French and Turkish

Very similar Not similar at all

Samples of closed-questions on the difficulty level of the properties (tested) in L3 French:

How do you rate the following in terms of difficulty for you?

a) Gender of nouns (e.g. remembering whether livre is masculine (le) or feminine (la))?

Very Easy__ Very Difficult

b) Choosing the right article with nouns (e.g. remembering what goes in the gap in (le/un) Elle va acheter vélo) as opposed to (Elle va acheter vélo de son cousin)

Very Easy Very Difficult

Samples of closed-questions on L2 English effect on L3A:

Did learning English first help when you came to learn French?

Very much Not at all

\section{Samples of Open-ended questions}

The questionnaire also consisted of open-ended questions, which asked participants to briefly justify their rating choices, as shown by the examples below:

Think about the following properties (gender, number concord, definiteness) in which property (ies) do you think:

a) Your mother tongue and English are similar/different? Briefly explain How?

b) Your mother tongue and French are similar/different? Briefly explain How?

c) English and French are similar/different? Briefly explain How?

\subsection{Quantitative Results}




\subsubsection{Gender}

\subsubsection{Multiple Choice Translation (MCT) Test}

The overall results on gender in the MCT test are presented in table 4. Target-like use means that participants selected the translation for an item where both Adj and D agree with the head $\mathrm{N}$ that has been assigned target gender. Non-target-like use means the selection of any of the other three sentences for an item.

Table 4: Mean percentage of Target-like performance by L1

\begin{tabular}{|l|l|l|l|}
\hline \multirow{2}{*}{ Performance } & \multicolumn{2}{|l|}{ L3 learners divided by L1 } & $\begin{array}{l}\text { Native } \\
(\mathrm{N}=10)\end{array}$ \\
\cline { 2 - 4 } & Spanish $(\mathrm{N}=22)$ & Turkish $(\mathrm{N}=16)$ & $120 / 120(100 \%)$ \\
\hline Target-like use & $257 / 264(97.34 \%)$ & $121 / 192 \quad(63.02 \%)$ & $0 / 120(0 \%)$ \\
\hline Non Target-like use & $7 / 264 \quad(2.65 \%)$ & $71 / 192 \quad(36.97 \%)$ & 0 \\
\hline
\end{tabular}

A one-way ANOVA [dependent variable $=$ target-like use; independent group variable $=$ experimental groups divided by L1] was carried out and showed a significant effect for $\mathrm{L} 1$ group $[F(2,45)=91.782, p=.0001]$. A posthoc test using Bonferroni adjustments was carried out and showed a significant difference between the French and Turkish groups $(p=.001)$, also between the Spanish and Turkish groups $(p=.0001)$, but no significant difference between the Spanish group and the French control group $(p=1.000)$.

In order to test whether the performance of the Spanish and Turkish groups was influenced by L1 or L2, two comparisons were made. First a comparison between Spanish and Turkish participants with advanced proficiency in English. If transfer is determined by the L2, this was expected to be most visible in those with high proficiency in the L2. Secondly, a comparison between those with low intermediate proficiency in English, where it was expected that any evidence of L1 influence would be most visible. Results of both comparisons are presented in table 5.

Table 5: Target-like performance of $L 2$ sub-groups in each $L 1$ group by gender type

\begin{tabular}{|l|l|l|l|l|l|}
\hline L1 L2 prof level by & $\begin{array}{l}\text { Adv Spanish } \\
(\mathrm{N}=13)\end{array}$ & $\begin{array}{l}\text { LI Spanish } \\
(\mathrm{N}=9)\end{array}$ & $\begin{array}{l}\text { Adv Turkish } \\
(\mathrm{N}=10)\end{array}$ & $\begin{array}{l}\text { LI Turkish } \\
(\mathrm{N}=6)\end{array}$ & $\begin{array}{l}\text { French } \\
\text { Natives } \\
\text { N=10) }\end{array}$ \\
\hline $\begin{array}{l}\text { Target-like use on } \\
\text { gender concord on A }\end{array}$ & $\begin{array}{l}155 / 156 \\
(99.35 \%)\end{array}$ & $\begin{array}{l}107 / 108 \\
(99.07 \%)\end{array}$ & $\begin{array}{l}113 / 120 \\
(94.16 \%)\end{array}$ & $\begin{array}{l}65 / 72 \\
(90.27 \%)\end{array}$ & $\begin{array}{l}120 / 120 \\
(100 \%)\end{array}$ \\
\hline $\begin{array}{l}\text { Target-like use on } \\
\text { gender concord on Det }\end{array}$ & $\begin{array}{l}156 / 156 \\
(100 \%)\end{array}$ & $\begin{array}{l}107 / 108 \\
(99.07 \%)\end{array}$ & $\begin{array}{l}118 / 120 \\
(98.33 \%)\end{array}$ & $\begin{array}{l}71 / 72 \\
(98.61 \%)\end{array}$ & $\begin{array}{l}120 / 120 \\
(100 \%)\end{array}$ \\
\hline $\begin{array}{l}\text { Target-like use on } \\
\text { gender assignment }\end{array}$ & $\begin{array}{l}154 / 156 \\
(98.71 \%)\end{array}$ & $\begin{array}{l}106 / 108 \\
(98.14 \%)\end{array}$ & $\begin{array}{l}86 / 120 \\
(71.66 \%)\end{array}$ & $\begin{array}{l}52 / 72 \\
(72.61 \%)\end{array}$ & $\begin{array}{l}120 / 120 \\
(100 \%)\end{array}$ \\
\hline
\end{tabular}

A mixed factorial ANOVA was carried out (within-subjects variable $1=$ gender type (target use of gender concord on Adj, target use of gender concord on Det and target use of gender assignment) and between-subjects factor $=\mathrm{LI}$ group). Results showed a significant effect for gender type $[\mathrm{F}(2,26)=16.027, p=.001]$ and a significant interaction between gender type and L2 groups, $[\mathrm{F}(2,42)=13.783, p=.003]$. A between-subject comparison showed a significant difference between the Adv Spanish and Adv Turkish groups $[\mathrm{F}(1,21)=48.640, p=.0001 *]$. A between subject-comparison showed a significant difference between the LI Spanish and LI Turkish groups [F(1,13)=150.176, $p=.0001]$.

A second mixed factorial ANOVA was carried out (within-subjects variable $1=$ gender type (target use of gender concord on Adj, target use of gender concord on Det and target use of gender assignment) and between-subjects factor $=\mathrm{Adv}$ groups). Results also showed a significant effect for gender type $\left[\mathrm{F}(2,42)=39.660, p=.0001^{*}\right]$ and a significant interaction between gender type and L2 groups, $[\mathrm{F}(2,42)=33.588, p=.0001 *]$. A between-subject comparison showed a significant difference between the Adv Spanish and Adv Turkish groups $[\mathrm{F}(1,21)=48.640$, $p=.0001 *$.

\subsubsection{Acceptability Sentence Correction (ASC) Test}

The results of overall performance on gender in the ASC are presented in table 6.

Table 6: Mean percentage of Target-like performance by $\mathrm{L1}$

\begin{tabular}{|l|l|l|l|}
\hline \multirow{2}{*}{ Performance } & \multicolumn{2}{|l|}{ L3 learners divided by L1 } & $\begin{array}{l}\text { Native } \\
(\mathrm{N}=10)\end{array}$ \\
\cline { 2 - 4 } & Spanish $(\mathrm{N}=22)$ & Turkish $(\mathrm{N}=16)$ & $159 / 160(99.37 \%)$ \\
\hline Target-like use & $340 / 352 \quad(96.59 \%)$ & $144 / 256 \quad(56.25 \%)$ & $1 / 160(0.62 \%)$ \\
\hline Non Target-like use & $12 / 352(3.40 \%)$ & $112 / 256(43.75 \%)$ & \\
\hline
\end{tabular}


A One-way ANOVA was carried [dependent variable $=$ target-like use; independent group variable $=$ Experimental groups divided by L1]. Results showed a significant effect of $\mathrm{L} 1$ group $[F(2,45)=207.832, p=.0001]$. These results were further adjusted using a post hoc Bonferroni test and results revealed a significant difference between the French control group and Turkish participants $(p=.0001)$, between the Spanish and Turkish groups $(p=.0001)$, but no significant difference between the French control group and the Spanish group $(p=.826)$.

Again, in order to measure likely L2 and L1 influence, results were further examined by proficiency level in L2 English.

Table 7: Mean percentage of Target-like performance by gender type and definiteness by L2 proficiency within L1 groups

\begin{tabular}{|l|l|l|l|l|l|}
\hline \multicolumn{1}{|c|}{ Prof level by language } & $\begin{array}{l}\text { Adv Spanish } \\
(\mathrm{N}=13)\end{array}$ & $\begin{array}{l}\text { LI Spanish } \\
(\mathrm{N}=9)\end{array}$ & $\begin{array}{l}\text { Adv Turkish } \\
(\mathrm{N}=10)\end{array}$ & $\begin{array}{l}\text { LI Turkish } \\
(\mathrm{N}=6)\end{array}$ & $\begin{array}{l}\text { French } \\
\text { Natives } \\
\text { N=10) }\end{array}$ \\
\hline $\begin{array}{l}\text { Property } \\
\text { conct-like use on gender on A }\end{array}$ & $\begin{array}{l}48 / 52 \\
(92.30 \%)\end{array}$ & $\begin{array}{l}36 / 36 \\
(100 \%)\end{array}$ & $\begin{array}{l}26 / 40 \\
(65 \%)\end{array}$ & $\begin{array}{l}13 / 24 \\
(54.16 \%)\end{array}$ & $\begin{array}{l}39 / 40 \\
(97.5 \%)\end{array}$ \\
\hline $\begin{array}{l}\text { Target-like use on gender } \\
\text { concord on Det }\end{array}$ & $50 / 52$ & $35 / 36$ & $30 / 40$ & $13 / 24$ & $40 / 40$ \\
\hline $\begin{array}{l}\text { Target-like use on gender } \\
\text { assignment }\end{array}$ & $(96.15 \%)$ & $(97.22 \%)$ & $(75 \%)$ & $(54.16 \%)$ & $(100 \%)$ \\
\hline
\end{tabular}

A mixed factorial ANOVA was carried out (within-subjects variable $1=$ gender type (target use of gender concord on Adj, target use of gender concord on Det and target use of gender assignment) and between-subjects factor = LI group). Results showed a significant effect for gender type $[\mathrm{F}(2,26)=1.957, p=.162]$ and a significant interaction between gender type and L2 groups, $[\mathrm{F}(2,26)=.348, p=.709]$. A between subject-comparison showed a highly significant difference between the LI Spanish and LI Turkish groups $[\mathrm{F}(1,13)=138.610, p=.0001 *]$.

A second mixed factorial ANOVA was carried out (within-subjects variable $1=$ gender type (target use of gender concord on Adj, target use of gender concord on Det and target use of gender assignment) and between-subjects factor $=\operatorname{Adv}$ groups). Results also showed a significant effect for gender type $[\mathrm{F}(2,42)=11.004, p=.003]$ and a significant interaction between gender type and L2 groups, $[\mathrm{F}(2,42)=7.112, p=.002]$. A between-subject comparison showed a highly significant difference between the Adv Spanish and Adv Turkish groups $[\mathrm{F}(1,21)=76.812, p=.0001 *]$.

\subsubsection{Number}

\subsubsection{Multiple Choice Translation (MCT) Test}

The overall results on number concord in the MCT test are presented in table 8 below.

Table 8: Mean percentage of Target-like performance by $\mathrm{L} 1$

\begin{tabular}{|l|l|l|l|}
\hline \multirow{2}{*}{ Performance } & \multicolumn{2}{|l|}{ L3 learners divided by L1 } & $\begin{array}{l}\text { Native } \\
(\mathrm{N}=10)\end{array}$ \\
\cline { 2 - 5 } & Spanish $(\mathrm{N}=22)$ & Turkish $(\mathrm{N}=16)$ & $60 / 60(100 \%)$ \\
\hline Target-like use & $126 / 132(95.45 \%)$ & $83 / 96(86.45 \%)$ & $0 / 60(0 \%)$ \\
\hline Non Target-like use & $6 / 132 \quad(4.54 \%)$ & $13 / 96(13.54 \%)$ & $0 / 60(0 \%)$ \\
\hline
\end{tabular}

A one-way ANOVA [dependent variable $=$ mean target-like use; independent group variable $=$ Experimental groups divided by L1] was conducted and results showed a significant effect for L1 groups $[F(2,45)=7.111$, $p=.002]$. Adjustments using post-hoc test Bonferroni showed a significant difference between French native speakers and the Turkish group ( $p=.003)$, and also between the Spanish and the Turkish groups $(p=.019)$, but no significant difference between the French and the Spanish groups $(p=.657)$. As for gender, the results were further investigated for the effects of L2 proficiency. These are presented in table 9.

Table 9: Mean percentage of Target-like performance by property type and L2 proficiency within L1 groups

\begin{tabular}{|c|c|c|c|c|c|}
\hline $\begin{array}{l}\text { Prof level by } \\
\text { language }\end{array}$ & $\begin{array}{l}\text { Adv Spanish } \\
(\mathrm{N}=13)\end{array}$ & $\begin{array}{l}\text { LI Spanish } \\
(\mathrm{N}=9)\end{array}$ & $\begin{array}{l}\text { Adv Turkish } \\
\quad(\mathrm{N}=10)\end{array}$ & $\begin{array}{l}\text { LI Turkish } \\
(\mathrm{N}=6)\end{array}$ & $\begin{array}{l}\text { French Natives } \\
\mathrm{N}=10 \text { ) }\end{array}$ \\
\hline $\begin{array}{l}\text { Target-like use on Number } \\
\text { concord on D }\end{array}$ & $\begin{array}{l}78 / 78 \\
(100 \%)\end{array}$ & $\begin{array}{l}53 / 54 \\
(98.14 \%)\end{array}$ & $\begin{array}{l}60 / 60 \\
(100 \%)\end{array}$ & $\begin{array}{l}36 / 36 \\
(100 \%)\end{array}$ & $\begin{array}{l}60 / 60 \\
(100 \%)\end{array}$ \\
\hline $\begin{array}{l}\text { Target-like use on Number } \\
\text { concord on A }\end{array}$ & $\begin{array}{l}75 / 78 \\
(96.15 \%)\end{array}$ & $\begin{array}{l}52 / 54 \\
(96.29 \%)\end{array}$ & $\begin{array}{l}54 / 60 \\
(90 \%)\end{array}$ & $\begin{array}{l}32 / 36 \\
(88.88 \%)\end{array}$ & $\begin{array}{l}60 / 60 \\
(100 \%)\end{array}$ \\
\hline $\begin{array}{l}\text { Target-like use on Number } \\
\text { concord on D and A }\end{array}$ & $\begin{array}{l}78 / 78 \\
(100 \%)\end{array}$ & $\begin{array}{l}54 / 54 \\
(100 \%)\end{array}$ & $\begin{array}{l}58 / 60 \\
(96.66 \%)\end{array}$ & $\begin{array}{l}35 / 36 \\
(97.22 \%)\end{array}$ & $\begin{array}{l}60 / 60 \\
(100 \%)\end{array}$ \\
\hline
\end{tabular}


These results were tested statistically using a mixed factorial ANOVA for each of the two L2 sub-groups (withinsubjects variable $1=$ Number concord type (target use of number concord on A, target use of number concord on D and target use of number concord on both $\mathrm{D}$ and $\mathrm{A}$ ) and between-subjects factor $=$ LI group). Results showed a significant effect for number concord type $[\mathrm{F}(2,26)=4.067, p=.029]$, but no significant interaction between number concord and L2 groups $[\mathrm{F}(2,26)=1.667, p=.208]$. A between-subjects comparison showed no significant difference between the LI Spanish and LI Turkish groups $[\mathrm{F}(1,13)=1.712, p=.213]$. Such statistical results indicate no significant difference between LI Turkish speakers and LI Spanish speakers when they effectively learn French without much intervening L2 knowledge.

A second mixed factor ANOVA was carried out and results showed no statistically significant main effect for number concord type $[\mathrm{F}(1,21)=1.430, p=.251]$, but there was a significant interaction between number concord type and L2 group, $[\mathrm{F}(2,42)=7.869, p=.001]$. Unlike the results of the LIs, however, a between-subjects comparison showed a significant difference between the Adv Spanish and Adv Turkish sub-groups $[\mathrm{F}(1,21)=4.864, p=.039]$. Such results indicate that there is indeed a significant difference between Adv Spanish speakers' treatment of number concord and their counterparts Adv Turkish speakers, which imply that L2 does not seem to play any significant role in the performance of both sub-groups; otherwise, there would be no significant difference between both groups.

\subsubsection{Acceptability Sentence Correction (ASC) Test}

Overall results on number concord in the ASC test are presented in table 10, and a breakdown of results by proficiency in L2 English are displayed in table 11.

Table 10: Mean percentage of Target-like performance by $L 1$

\begin{tabular}{|l|l|l|l|}
\hline \multirow{2}{*}{ Performance } & \multicolumn{2}{|l|}{ L3 learners divided by L1 } & $\begin{array}{l}\text { Native } \\
(\mathrm{N}=10)\end{array}$ \\
\cline { 2 - 5 } & Spanish $(\mathrm{N}=22)$ & Turkish $(\mathrm{N}=16)$ & speakers \\
\hline Target-like use & $169 / 176(96.02 \%)$ & $114 / 128(89.06 \%)$ & $780(96.66 \%)$ \\
\hline Non Target-like use & $7 / 176(3.97 \%)$ & $14 / 128(10.93 \%)$ & $2 / 80(2.08 \%)$ \\
\hline
\end{tabular}

A One-way ANOVA was carried out [dependent variable= target-like use; independent group variable Experimental groups divided by L1] and results corroborated the descriptive percentages above. There was a significant effect for L1 group $[F(2,45)=6.144, p=.003]$, and a significant difference between the three experimental groups. Adjustments using post hoc Bonferroni test revealed a significant difference between the French control group and the Turkish group $(p=.012)$, and also between the Spanish and Turkish groups ( $p=.014)$, but no significant difference between the French control group and the Spanish group $(p=1.000)$.

Table 11: Mean percentage of Target-like performance by Number property and L2 proficiency levels within $\mathbf{L} 1$ groups

\begin{tabular}{|c|c|c|c|c|c|}
\hline $\begin{array}{l}\text { Prof level by language } \\
\text { Property }\end{array}$ & $\begin{array}{l}\text { Adv Spanish } \\
(\mathrm{N}=13)\end{array}$ & $\begin{array}{l}\text { LI Spanish } \\
(\mathrm{N}=9)\end{array}$ & $\begin{array}{l}\text { Adv Turkish } \\
\quad(\mathrm{N}=10)\end{array}$ & $\begin{array}{l}\text { LI Turkish } \\
(\mathrm{N}=6)\end{array}$ & $\begin{array}{l}\text { French } \\
\text { Natives } \\
\mathrm{N}=10)\end{array}$ \\
\hline $\begin{array}{l}\text { Target-like use on } \\
\text { Number concord on D }\end{array}$ & $\begin{array}{l}104 / 104 \\
(100 \%)\end{array}$ & $\begin{array}{l}72 / 72 \\
(100 \%)\end{array}$ & $\begin{array}{l}79 / 80 \\
(98.75 \%)\end{array}$ & $\begin{array}{l}47 / 48 \\
(97.91 \%)\end{array}$ & $\begin{array}{l}80 / 80 \\
(100 \%)\end{array}$ \\
\hline $\begin{array}{l}\text { Target-like use on } \\
\text { Number concord on A }\end{array}$ & $\begin{array}{l}103 / 104 \\
(99.03 \%)\end{array}$ & $\begin{array}{l}67 / 72 \\
(93.05 \%)\end{array}$ & $\begin{array}{l}76 / 80 \\
(95 \%)\end{array}$ & $\begin{array}{l}43 / 48 \\
(89.58 \%)\end{array}$ & $\begin{array}{l}78 / 80 \\
(97.5 \%)\end{array}$ \\
\hline $\begin{array}{l}\text { Target-like use } \\
\text { Number concord on } \\
\text { and A }\end{array}$ & $\begin{array}{l}104 / 104 \\
(100 \%)\end{array}$ & $\begin{array}{l}71 / 72 \\
(98.61 \%)\end{array}$ & $\begin{array}{l}79 / 80 \\
(98.75 \%)\end{array}$ & $\begin{array}{l}46 / 48 \\
(95.83 \%)\end{array}$ & $\begin{array}{l}80 / 80 \\
(100 \%)\end{array}$ \\
\hline
\end{tabular}

A mixed factorial repeated measures ANOVA [Within subjects variables= number property, between subjects factor= LI group] was carried and results showed a significant effect for number concord type $[F(2,26)=5.489$, $p=.010]$, but there was no significant interaction between the property number concord and L2 groups $[\mathrm{F}(2,26)=.041, p=.960]$. However, unlike the MCT results, a between-subjects comparison revealed a significant difference between the LI Spanish group and the LI Turkish group [ $\mathrm{F}(1,13)=6.240, p=.027]$.

Results of the Adv group were slightly similar to the LI ones. There was no significant effect for number concord type $[\mathrm{F}(2,42)=3.357, p=.058]$, and no significant interaction between the property number concord and L2 groups $[\mathrm{F}(2,42)=1.176, p=.311]$. However, a between-subjects comparison revealed a significant difference between the Adv Spanish group and the Adv Turkish group $[\mathrm{F}(1,21)=6.101, p=.022]$, which suggests that L2 cannot be a significant factor for this test; otherwise the two sub-groups would show similar results. 


\subsubsection{Article choice}

\subsubsection{Multiple Choice Translation (MCT) Test}

The overall results on article choice on the MCT are presented in table 13. The Spanish-speaking participants closely approximate native control performance. The Turkish-speaking participants, although performing above chance, were less target-like in their choice of articles.

Table 12: MCT mean percentage of Target-like performance by L1

\begin{tabular}{|l|l|l|l|}
\hline & Spanish $(\mathrm{N}=22)$ & Turkish $(\mathrm{N}=16)$ & French Natives $(\mathrm{N}=10)$ \\
\hline Target-like use & $249 / 264(94.31 \%)$ & $155 / 192(80.72 \%)$ & $119 / 120(99.16 \%)$ \\
\hline Non Target-like use & $15 / 264(5.68 \%)$ & $37 / 192(19.27 \%)$ & $1 / 120(0.83 \%)$ \\
\hline
\end{tabular}

A one way ANOVA was carried out [dependent variable=mean target-like use; independent group variable=Experimental groups divided by L1] and results showed a significant difference between these experimental groups $[F(2,45)=20.452, p=.0001]$. Adjustments using a post-hoc Bonferroni test showed a significant difference between the French native speakers and the Turkish group $(p=.0001)$, and also between the Spanish and the Turkish groups $(p=.0001)$, but no significant difference between the French natives and the Spanish group $(p=.352)$. Choice of articles by context and by proficiency in L2 English is presented in table 13.

Table 13: MCT Article choice by definiteness and L2 proficiency within L1 groups

\begin{tabular}{|l|l|l|l|l|l|}
\hline \multirow{3}{*}{ Context } & \multicolumn{3}{|l|}{ L3 learners divided by L1 and L2 proficiency } & \multirow{2}{*}{ French Natives } \\
\cline { 2 - 5 } & L1 Spanish & L1 Turkish & \\
\cline { 2 - 6 } & Adv (N=13) & LI (N=9) & Adv (N=10) & LI (N=6) & \\
\hline [+Def] & $39 / 78(94.87 \%)$ & $52 / 54(96.29 \%)$ & $58 / 60(96.66 \%)$ & $29 / 36(80.55 \%)$ & $30 / 60(100 \%)$ \\
\hline$[-D e f]$ & $37 / 78(92.30 \%)$ & $51 / 54(94.44 \%)$ & $59 / 30(98.33 \%)$ & $18 / 36(61.11 \%)$ & $59 / 60(98.33 \%)$ \\
\hline
\end{tabular}

A one way ANOVA was carried out for the LI sub-groups of each L1 group [dependent variable $1=$ mean targetlike use [+Def], dependent variable 2 [-Def]; independent group variable= LIs of each L1 group]. Results of the definite context showed a significant difference between the Spanish LIs and their counterparts Turkish LIs $[F(1,14)=7.962, p=.014]$. Results of the indefinite context also showed a significant difference between the two sub-groups $[\mathrm{F}(1,14)=24.239, p=.0001 *]$.

Results of the Adv group were somewhat different from those of the LIs. Results of the definite context showed no significant difference between the Spanish LIs and their counterparts Turkish LIs $[\mathrm{F}(1,21)=3.437, p=.078]$. Results of the indefinite context also showed no significant difference between the two sub-groups $[\mathrm{F}(1,21)=2.774$, $p=.111$ ], implying that both sub-groups of higher L2 proficiency levels are performing alike unlike the results of the LIs whereby the Spanish LIs outperformed the Turkish ones. Such results indicate that L2 English seems to have an effect on the performance of the Turkish subjects with advanced L2 proficiency but not on the performance of the Spanish group of a comparable L2 proficiency level.

\subsubsection{Acceptability Sentence Correction (ASC) Test}

Table 14: ASC test: Mean percentage of Target-like performance by L1

\begin{tabular}{|l|l|l|l|}
\hline & Spanish $(\mathrm{N}=22)$ & Turkish $(\mathrm{N}=16)$ & French Natives $(\mathrm{N}=10)$ \\
\hline Target-like use & $340 / 352(96.59 \%)$ & $219 / 256(85.54 \%)$ & $157 / 160(98.12 \%)$ \\
\hline Non Target-like use & $12 / 352(3.40 \%)$ & $37 / 256(14.45 \%)$ & $3 / 160(1.87 \%)$ \\
\hline
\end{tabular}

A one way ANOVA was carried out [dependent variable = mean target-like use; independent group variable=Experimental groups divided by L1] and results showed a significant difference between these experimental groups $[F(2,45)=12.697, p=.0001]$. Adjustments using a post-hoc Bonferroni test showed a significant difference between the French control group and the Turkish group $(p=.0001)$, and also between the Spanish and the Turkish groups $(p=.0001)$, but no significant difference between the French group and the Spanish one $(p=1.000)$. Results are further broken down by context and L2 proficiency (table 15).

Table 15: ASC test: Article choices by definiteness and L2 proficiency within L1 groups

\begin{tabular}{|c|c|c|c|c|c|}
\hline \multirow{3}{*}{ Context } & \multicolumn{4}{|c|}{ L3 learners divided by L1 and L2 proficiency } & \multirow{3}{*}{$\begin{array}{l}\text { French Natives } \\
(\mathrm{N}=10)\end{array}$} \\
\hline & \multicolumn{2}{|l|}{ L1 Spanish } & \multicolumn{2}{|l|}{ L1 Turkish } & \\
\hline & $\operatorname{Adv}(\mathrm{N}=13)$ & $\mathrm{LI}(\mathrm{N}=9)$ & $\operatorname{Adv}(\mathrm{N}=10)$ & $\mathrm{LI}(\mathrm{N}=6)$ & \\
\hline [+Def] & $102 / 104(98.07 \%)$ & $69 / 72(95.83 \%)$ & $75 / 80(93.75 \%)$ & $41 / 48(80.55 \%)$ & $79 / 80(98.75 \%)$ \\
\hline [-Def] & 98/104 (92.30\%) & $71 / 72(98.61 \%)$ & $75 / 80(93.75 \%)$ & $28 / 48(58.33 \%)$ & $78 / 80(97.5 \%)$ \\
\hline
\end{tabular}


As shown above, Spanish Adv and Turkish Adv sub-groups behaved in an almost similar target-like manner in both [ \pm Def] settings. However, such results are not the same for the LIs because the Spanish LIs appeared more target like than the Turkish LIs. These results were statistically tested using a one way ANOVA for each L2 sub-group: for the LI sub-groups [dependent variable 1 = mean target-like use [+Def], dependent variable 2 [-Def]; independent group variable $=$ LIs of each L1 group]. Results of the definite context showed a significant difference between the Spanish LIs and their counterparts Turkish LIs $[\mathrm{F}(1,13)=6.724, p=.022]$. Results of the indefinite context also showed a significant difference between the two sub-groups $[\mathrm{F}(1,13)=115.084, p=.0001 *]$, which implies that the Spanish subjects with lower L2 proficiency outperformed the Turkish subjects of a comparable L2 proficiency level.

Results of the Adv group were somewhat different. Results of the definite context showed no significant difference between the Spanish LIs and their counterparts Turkish LIs $[\mathrm{F}(1,21)=3.393, p=.080]$. Results of the indefinite context also showed no significant difference between the two sub-groups $[\mathrm{F}(1,21)=.023, p=.882]$. Such results indicate that the Turkish Adv participants seem to have benefited from their higher proficiency level in L2 English (a language which grammaticalizes definiteness); this is why there was no significant difference between them and the Spanish Adv subjects. Similar results were also found in the MCT test.

\subsection{Qualitative Results: Questionnaire Comparing between L1, L2 and L3}

\subsubsection{Similarity between $L 1 / L 2$ and $L 3$}

In scoring the closed (rating) questions, the researcher divided the scale into seven equally spaced boxes, where each box referred to a specific degree. For example, questions asking about the similarity level between languages would be scored as shown below.
1- Box 1: Very similar
2- Box 2: Similar
3- Box 3: Slightly similar
4- Box 4: Neutral (neither similar nor different)
5- Box 5: Slightly different
6- Box 6: Different
7- Box 7: Very different

The percentages of the ratings of the two groups are summarized in figures 1 and 2 below:

Fig. 1: Ratings of the Spanish group

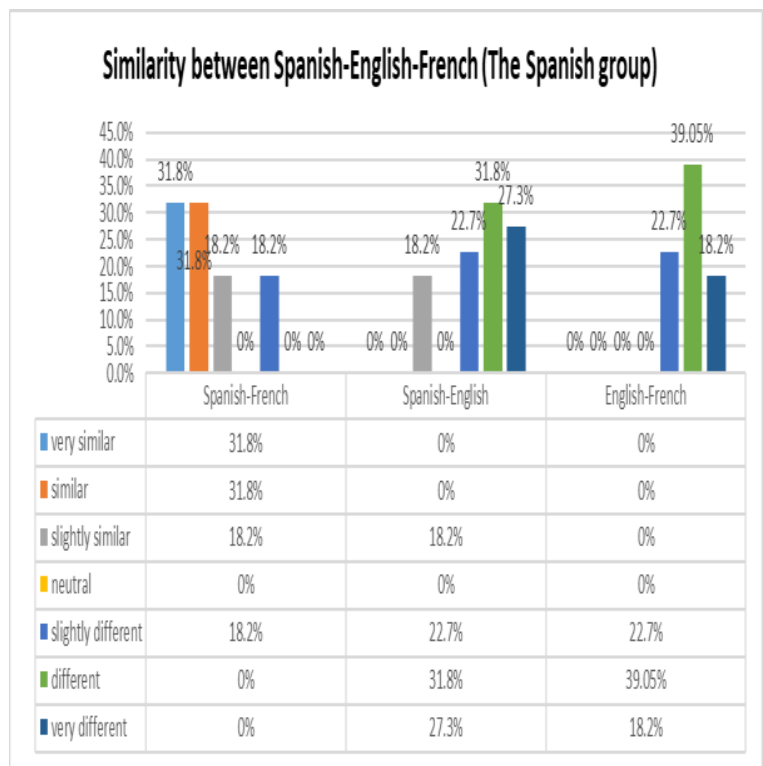

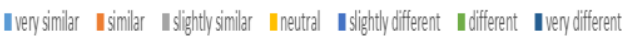

Fig. 2: Ratings of the Turkish group

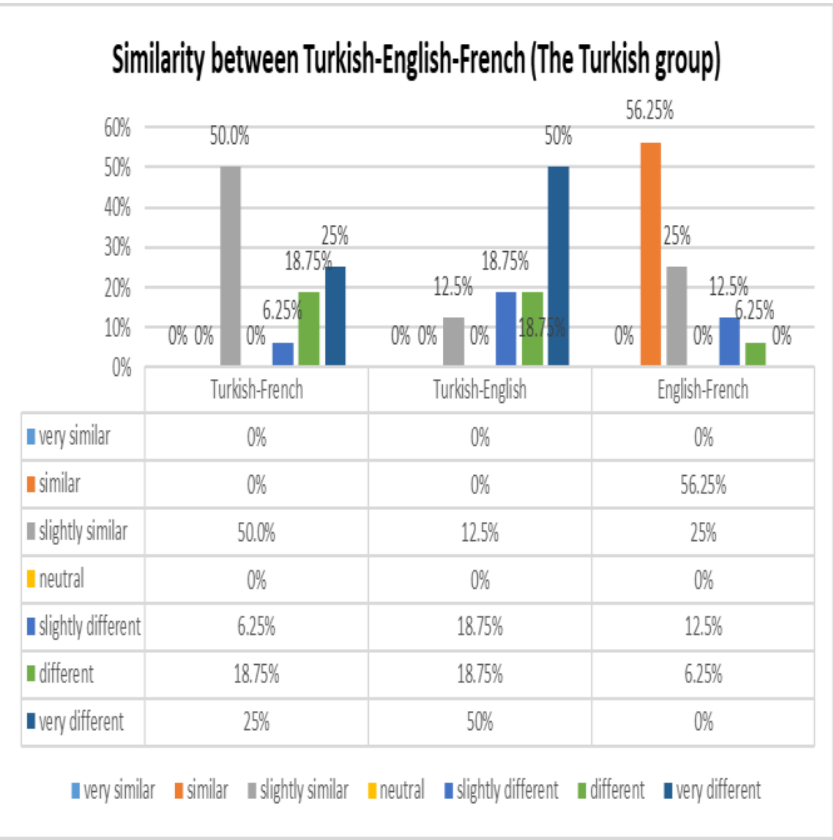

What is noticeable here is that while the Turkish subjects consider English and French to be relatively similar languages, the Spanish subjects consider English-French to be very different. One possible justification for this difference in perspectives is that for the Spanish group, whose L1 is typologically very similar to French, English is different from French compared to Spanish, whereas for the Turkish group neither L1 Turkish nor L2 English is typologically very similar to French. Hence, both Turkish/English are similar to French in certain properties but also different vis-à-vis other properties according to the Turkish group. 


\subsubsection{The role of $L 2$ in $L 3 A$}

Responses of the two groups to this question are summarized in figure 3 below.

a. Did learning English first help when you came to learn French?

Very helpful Not at all helpful

Fig. 3: The role of $L 2$ English in learning $L 3$ French

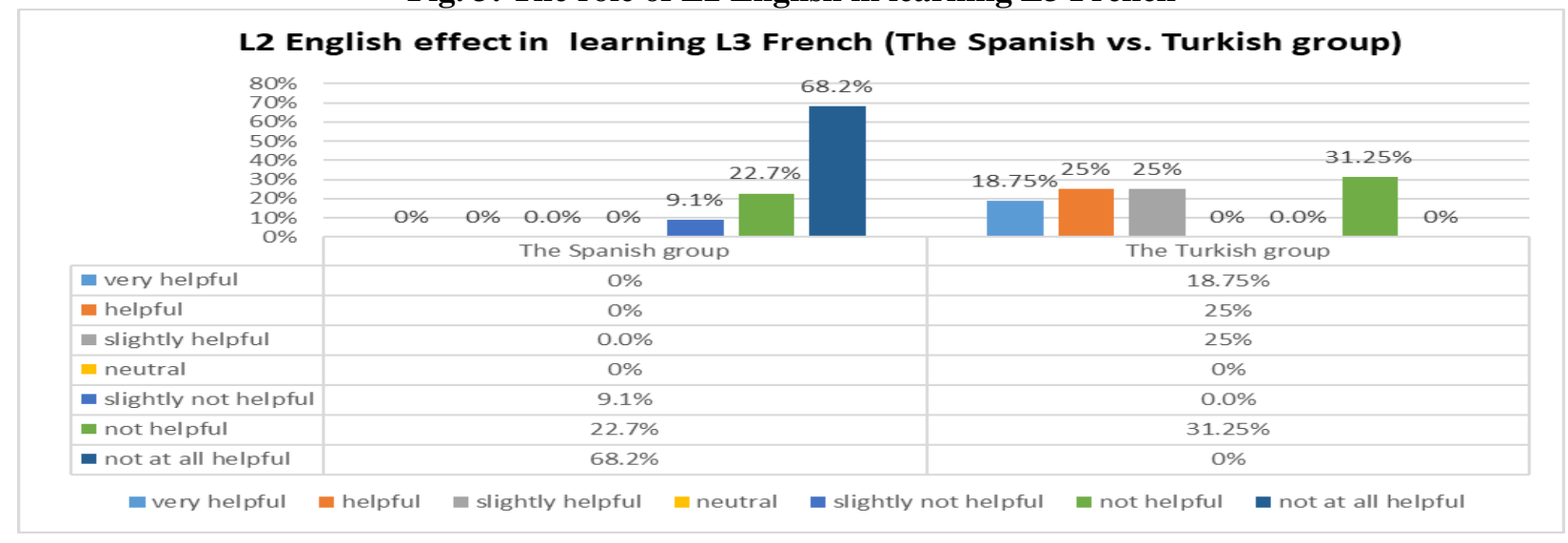

When asked about their justifications, most of the Spanish participants argue that Spanish is much closer to French than English to French. This is why they consider Spanish to have helped them much more than English in learning French. Many participants in the Turkish group, in contrast, consider English to have helped them in learning French because English shares some features with French. However, the Turkish subjects who rate English as being just slightly helpful or not helpful argue that though there are some similarities between English and French, they are quite few; this is why English is not very helpful. Hence, what is noticeable again is that for the Spanish group, English is very different from French compared to Spanish and, therefore, has not helped them much when learning French. In contrast, for the Turkish group, English is relatively similar to French; this is why they seem to find it quite helpful when learning L3 French.

\subsubsection{Similarity/Difference between $L 1 / L 2$ and $L 3$ regarding the property tested}

\subsubsection{Gender}

Most Spanish participants argue that Spanish and French are very similar regarding gender assignment and gender concord because both languages have gender. However, all Spanish subjects state that English is very different from French and Spanish for English does not have gender. Turkish participants, on the other hand, consider both Turkish and English to be very different from French regarding the property of gender since both languages are gender-free.

\subsubsection{Number Concord:}

All Spanish participants agree that Spanish and French are completely similar in number concord, but more than $70 \%$ of them consider English to be different from French and Spanish regarding number concord for English does not allow number inflection on Ds and Adjs.

Nine out of 16 Turkish participants, on the other hand, consider English and French to be similar because both languages have Ns that take a plural form while seven participants rate English to be different from French and justify their responses by the fact that English Adjs do not take an ' $s$ ' for the plural. Interestingly, only two participants out of the seven shed light on the fact that English Ds also do not take plural inflection. When asked about the difference between Turkish and French, the majority (11 out of 16) consider Turkish and French quite similar because Turkish nouns get inflected for plural ('ler' or 'lar'), whereas quite a few subjects (6/16) consider them as different because Turkish Adjs do not take a plural form unlike French Adjs. That shows that this group considers Turkish and French to be alike in number concord. Similarly, when asking about the similarity between Turkish and English, a few subjects consider the two languages to be different while the majority rate the pair to be similar.

\subsubsection{Article choice}

Almost all the Spanish participants consider Spanish and French to be typically alike concerning article choices and also English vs. French and Spanish. However, for no clear reasons, most Spanish participants consider Spanish and French to be much closer than English. 
Almost all the Turkish participants consider English and French to be very similar regarding the feature of definiteness, but the majority consider Turkish to be very different from both English and French simply because this language does not have articles.

\subsubsection{The difficulty level of the property tested}

\subsubsection{Gender}

Descriptive results of the Spanish participants show that both gender assignment and gender concord are rated as very easy features to learn in L3 French unlike the Turkish participants, who rate it as being very difficult. Noteworthy, although the Turkish participants rate the feature gender (both assignment and concord) as challenging, one can notice that they seem to find gender assignment more challenging than gender concord. This would be logical for once they know the gender of a given noun, assigning the right inflection to the Ds and Adjs might be less difficult (see figures 4 and 5 for more details).

Fig.4: Results on the difficulty level of gender assignment Fig. 5: Results on the difficulty level of gender concord in L3 French in L3 French
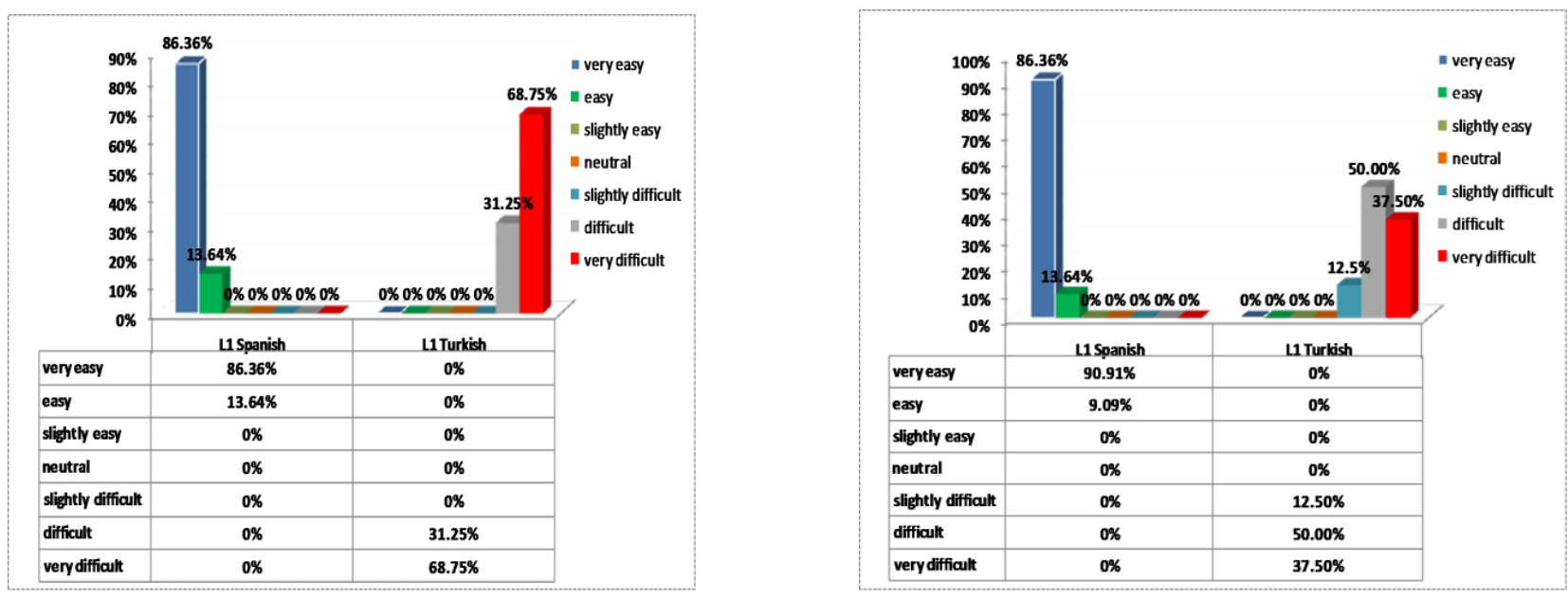

\subsubsection{Number concord}

Both Spanish and Turkish participants' responses have been almost alike to this question. The feature of number concord (on Ds and Adjs) seems to be easy for both groups, but it is much easier for the Spanish group than the Turkish one. In addition, number concord on Ds seems to be quite easier for the Turkish group than number concord on Adjs, as shown in figures 6 and 7.

Fig. 6: Results on the difficulty level of number concord on Ds in L3 French

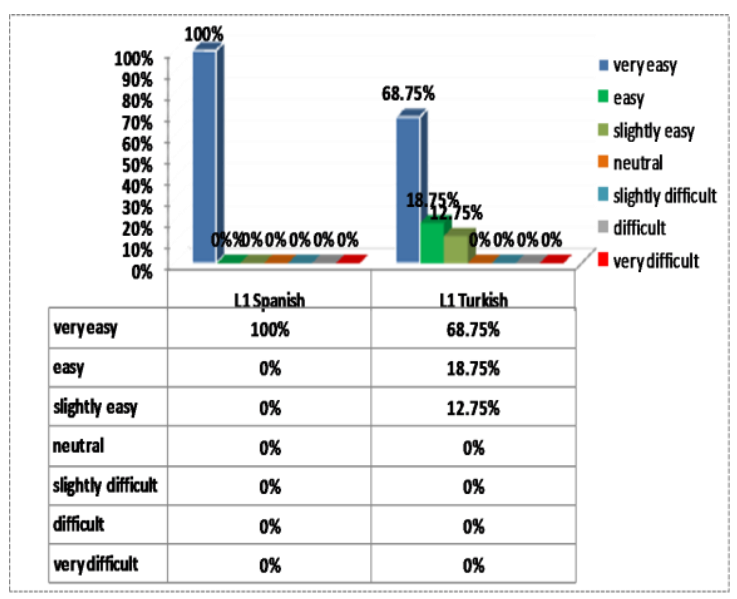

Fig.7: Results on the difficulty level of number concord on Adjs in L3 French

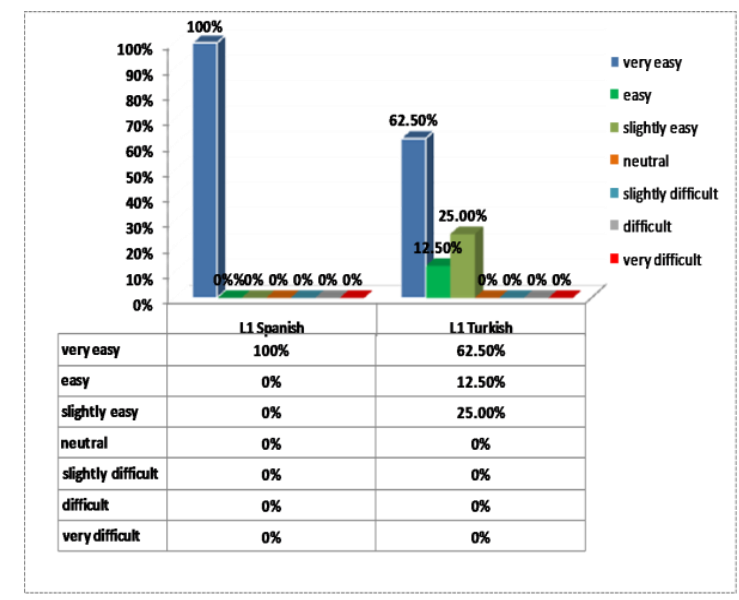

\subsubsection{Articles}

Results of the Spanish participants show that they seem to find the appropriate article selection in L3 French an easy property to learn and so do the Turkish participants. However, the distribution of the Turkish group's ratings was slightly different from that of the Spanish group, as shown in figure 8 below. 
Such findings imply that while both groups find article choice in L3 French an easy property to learn, the Spanish group seems to find it much easier than the Turkish group.

\section{Fig. 8: Results on the difficulty level of article choice in L3 French}

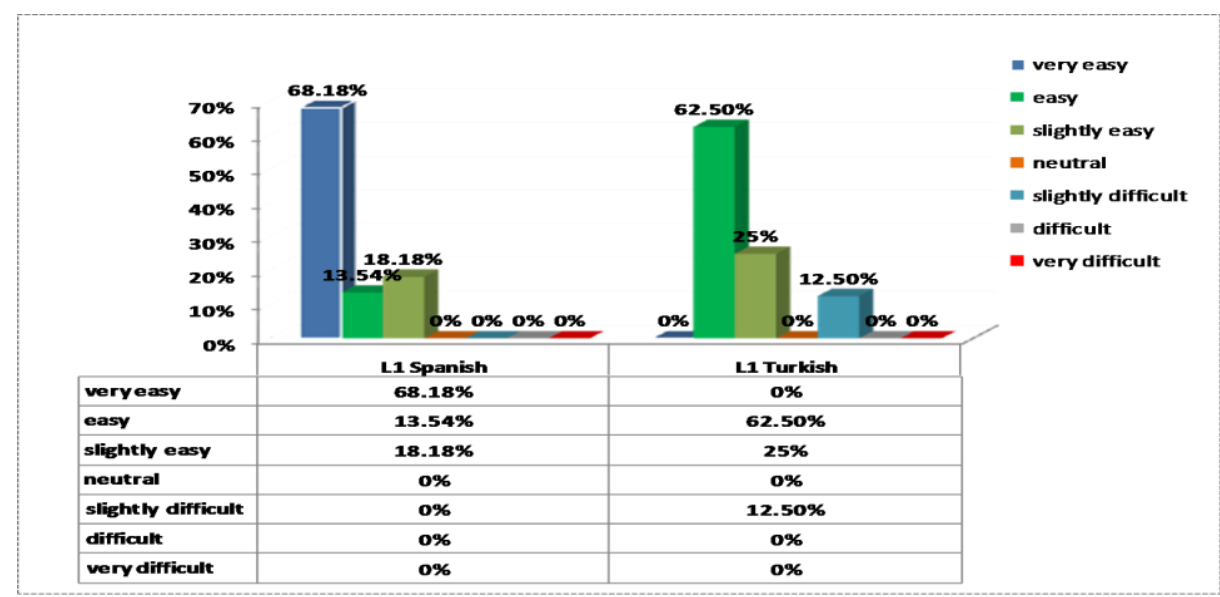

\subsection{Summary of results: Quantitative data vs. Qualitative data}

\section{Quantitative:}

- The Spanish participants (both of Advanced and Lower-intermediate L2 proficiency) outperformed their L1 Turkish counterparts in the treatment of gender in L3 French.

- Both Spanish and Turkish participants were target-like in number concord, but the Turkish subjects were less target-like than the Spanish ones. The Turkish subjects were more target-like in number concord on Ds than on Adjs. There was no effect for L2 proficiency kevel on the performance of each group on number concord.

- Both groups were target-like in article selection, but the Spanish group performed slightly better than the Turkish group. L2 proficiency seems to have an effect on the performance of the Turkish group on article selection. In fact, there was no significant difference between Spanish and Turkish subjects of advanced (Adv) L2 proficiency level, but there was significant difference between Spanish and Turkish subjects of low-intermediate L2 proficiency. That implies that Turkish subjects of Advanced L2 proficiency seem to have benefited from their higher proficiency in L2 English, a language that grammaticalizes definiteness.

\section{Qualitative:}

- The Spanish subjects consider Spanish to be typologically very similar to French, holistically, and also concerning the three properties tested. However, they consider English to be different from French even though it shares some properties with French (plural inflections on Ns and definiteness).

- The Turkish participants are aware that neither Turkish not English is typologically very similar to French. However, they are also aware that these two languages share some properties with French such as plural inflections on Ns and definiteness, but are different from French with regard to gender.

- While the Spanish participants found the three properties in question to be easy to learn in L3 French, the Turkish participants found gender to be the most difficult property compared to number concord and article selection. Number concord on Ds was also perceived to be much easier than number concord on Adjs for this group.

\section{Discussion}

Two research questions were addressed in this paper:

- Does transfer come from L1, L2, or both in early L3 French acquisition?

- If typological proximity is the driving variable for transfer, does it happen holistically (TPM) or on a property-by-property basis (The Scalpel Model and the LPM)

Answers to these questions in relation to the findings of the current study and the predictions of L3 models are addressed in this section (see sections 1.1. and 1.2. for further details on the predictions of the L3 models in questions).

\subsection{Wholesale Transfer Models}

\section{The L1-Privilege Model}


This model would predict the performance of the Spanish group in L3 French to be affected by L1 Spanish grammar while the Turkish group by L1 Turkish grammar. However, Turkish participants' target-like behavior in article choice (with over $80 \%$ of target-like use) is against the predictions of this model. Turkish is an article-free [ART] language whereas English is a [+ART] language that grammaticalizes definiteness. Hence, transfer was mainly derived from English. Another piece of evidence is that Turkish participants with advanced L2 proficiency outperformed those with lower-intermediate L2 proficiency in article selection in L3 French. That implies that the advanced participants benefited from their higher proficiency in L2 English. In addition, qualitative results of the questionnaire showed that the Turkish participants rated article choice in L3 French to be an easy property to learn thanks to the exposure they got from L2 English grammar. All of these findings show that the L1 privilege model cannot be supported by the findings of this study.

\section{The L2 Status Factor}

The L2 Status factor would expect the performance of the Spanish and Turkish groups in the three properties tested to be alike because they will be both influenced by L2 grammar. As such, both groups would be target-like in article selection and number concord, but non-target-like in gender. Findings of this study, nevertheless, did not support this scenario. The Spanish group outperformed the Turkish group in all the properties, even in number concord and article selection, which are features present in L2 English. In addition, the Spanish subjects were native-like in their treatment of gender in L3 French, although English is a gender-free language. Moreover, the Spanish subjects with advanced and lower-intermediate L2 level showed no difference across the three properties tested, indicating that L2 had no effect on their performance. A final piece of evidence is derived from the questionnaire; while the Turkish participants considered English to have helped them in learning some properties in L3 French such as number concord and article choice, the Spanish group denied any support gained from L2 English because for them Spanish was much more helpful. For these reasons, the L2 Status Factor predictions cannot be corroborated by these findings.

\section{The Typological Primacy Model (TPM)}

According to the TPM, lexical similarity is the first trigger that helps the parser identify whether a language is typologically similar to the L3 or not. Once the parser identifies which language is lexically more similar to the L3 than the other one, it will transfer all of the properties of that language to the L3 grammar on a wholesale transfer basis. Spanish is lexically closer to French than English to French while English is lexically closer to French than Turkish to French (see section 1.1. for further details). In light of these, the TPM would expect the Spanish participants to transfer all L1 Spanish properties and behave in a target-like manner in gender, number concord, and articles as they are all present in the Spanish grammar. However, the TPM would expect the Turkish group to transfer all the properties of L2 English on a wholesale basis. As such, the Turkish would be target-like in number concord and article selection, but non-target like in gender (assignment/concord). Overall, results of both groups seem to corroborate the TPM because Spanish and English seem to be indeed the sources of transfer for the Spanish and Turkish groups, respectively. However, deeper scrutiny of the findings reveals that there are two interpretations. The Spanish results fully corroborate the TPM because Spanish, which is typologically the most proximate to French compared to English, was the only source of transfer on the performance of this group as illustrated by the quantitative and qualitative findings. As for the Turkish group, nonetheless, English did not seem to be the unique source of transfer. There was a case of facilitative transfer from English (articles) but also facilitative and non-facilitative transfer from Turkish on number concord. First, comparison between Turkish groups with lower-intermediate L2 proficiency and those with advanced L2 proficiency on number concord, showed no significant difference between the two proficiency groups unlike their results on definiteness whereby the advanced Turkish group outperformed their lower-intermediate counterparts. Second, the fact that Turkish participants failed to acquire number concord on Adjs more than on Ds (articles in this study) could be due to negative transfer from L1 Turkish than L2 English. In fact, here is a difference between Turkish and English DPs (singular and plural):

\section{Turkish $\varnothing$ (D) N (sing.) Adj (sing.) $\varnothing(\mathrm{D}) \mathrm{N}(p l$.$) Adj (sing.)$}

\author{
English \\ Indef/Def (D) N (pl.) Adj (sing.) \\ $\varnothing$ (Indef)/ The (sing/Def) N (pl.) Adj (sing.)
}

That means, the input Turkish natives are exposed to in L1 Turkish consists of a DP that contains a noun (N) that is always inflected for plural and an Adj that is never inflected for plural, but they are never exposed to any article (neither plural or singular). Hence, the Turkish group's first exposure to an article that is inflected for plural was in L3 French. That explains why, they did not face challenges in number concord on articles, but they did so with plural inflection on Adjs.

If transfer, in contrast, would have come from English, then the Turkish natives are expected to be non-target like likewise in plural inflection on Ds and on Adjs, but that was not the case. Their results on number concord on Ds were slightly better than theirs on Adjs. 
This could imply that if the two languages are clearly typologically very similar i.e. (lexically, syntactically, morphologically, and are from the same family as in Spanish and French), the grammar of that language will be transferred on a wholesale transfer basis. However, if L1 or L2 is typologically distant from L3 even though one of them is lexically much closer to the L3 than the other, transfer (facilitative and non-facilitative) will be from both languages on a property-by-property basis. These interpretations are provided with caution here. Mirror groups and more properties are needed to have more conclusive interpretations ${ }^{6}$.

\subsection{Partial Transfer Models}

\section{The Cumulative Enhancement Model (CEM)}

The CEM argues that transfer is cumulative i.e. it could be from L1 and L2, but only facilitative (positive) transfer is possible, whereas non-facilitative transfer does not occur at all. The scenario would be that the Spanish group behave in a target-like manner in all the properties tested (positive transfer from L1 Spanish), whereas the Turkish group is supposed to be target-like in number concord and article choice, which are present in English, but there should be no negative effect of L1 Turkish and L2 English on their treatment of number inflection on Ds and Adjs or gender. Results of the Spanish group fully corroborate this model, and so are the results of the Turkish group on article choices. However, the fact that Turkish subjects were negatively transferring L1 Turkish grammar on number concord (no plural inflection on Adjs) in addition to their failure to be target-like in gender shows that nonfacilitative transfer is possible. In addition, the fact that the Spanish participants outperformed the Turkish group in article choice (though L2 English is [+ART] for both groups) reveals that the typological proximity between Spanish and French made the Spanish group at advantage compared to the Turkish one.

\section{The Linguistic Proximity Model and the Scalpel Model}

Both the LPM and the Scalpel Model argue that language acquisition is cumulative: L1 and L2 could be both sources of facilitative transfer. However, transfer is not holistic (contra the TPM), but rather on a property-byproperty basis while non-facilitative transfer is also possible (contra the CEM). As discussed above (in the TPM section), while the Spanish group's results corroborate holistic transfer from L1 Spanish, the Turkish group's results seem to support transfer on a property-by-property basis from both L1 Turkish (number concord) and from L2 English (articles). Noteworthy, however, as stated above, this study did not use mirror groups of participants, and Spanish and French were structurally alike in all the properties tested. Hence, using mirror groups L1 SpanishL2 English vs. L1 English-L2 Spanish or L1 Turkish-L2 English vs. L1 English vs. L2 Turkish and varieties of properties that are different even across the languages that are typologically alike would be efficient to draw more conclusive interpretations on whether transfer is holistic or property-based in early L3A.

In addition to typological similarity, the Scalpel Model argues that there are other variables that trigger transfer and can help explain the differential learnability of properties across different groups of L3 learners. However, as this study did not test these variables, no interpretations would be made in this regard. These variables will need to be further examined in future research.

\section{Conclusion}

It follows from the findings of this study that transfer in L3A can obtain from L1 and/or L2 both on a holistic basis and on a property-by-property basis, depending on the degree of typological similarity between the L1/L2 and the L3. Irrespective of the order of acquisition, the language that is (holistically) typologically the closest to L3 will be the source of transfer on a wholesale basis. However, in the absence of such clear holistic typological similarity, the parser would rely on property-by-property structural similarity between L1/L2 and the L3. Further research is always needed for more conclusive interpretations.

\section{References}

Ayoun, D. (1999a). Verb movement in French L2 acquisition. Bilingualism: Language and Cognition, 2, 103-125. Ayoun, D. (1999b). Bi-lingualism and the "mixed language" phenomenon. Bilingualism: Language and Cognition, 2, 187-189.

Bardel, C \& Falk, Y. (2007).The role of second language in third language acquisition: The case of Germanic syntax. Second Language Research, 23(4): 459-484.

\footnotetext{
${ }^{6}$ This study is part of a larger study (Ben Abbes, K, 2017). Adverb placement (frequency/manner adverbs) was also tested. French manner and frequency adverbs are placed post-verbally, whereas Spanish, though is a verb-raising language, does not exhibit verb raising consistently. It has optionality in the adverb positions (Ayoun, 1999a, 1999b). Overall results revealed that the Spanish subjects were transferring that optionality of L1 Spanish. This corroborates what is said in the current study; once L1 or L2 is clearly typologically alike to the L3, the parser would transfer the grammar of that language to the L3 on a holistic basis (facilitative and non-facilitative). 
Ben Abbes, K. (2016). The acquisition of French morpho-syntactic properties: Cross-linguistic Influence in the Learning of L3 French by Turkish/Spanish speakers who learned English as an L2. Unpublished Ph.D. dissertation, University of Essex.

Ben Abbes, K. (2017). Articles Choices in L3 French: Fluctuation or no Fluctuation. Language at the University of Essex (LangUE) Proceedings, pp. 8-22.

Berkes, É \& Flynn, S. (2012). Further evidence in support of the Cumulative-Enhancement Model: CP structure development. In Jennifer Cabrelli Amaro, Suzanne Flynn Flynn \& Jason Rothman (eds.), Third language acquisition in adulthood, 143-164. Amsterdam: John Benjamins. http://doi.org/10.1353/lan.2014.0011.

Brown, M.M. (2020). Grammatical gender acquisition in sequential trilinguals: Influence of a gendered L1 vs. L2. Proc Ling Soc Amer 5(1). 331-344. https://doi.org/10.3765/plsa.v5i1.4712

Falk, Y., \& Bardel, C. (2011). Object pronouns in German L3 syntax: Evidence for the L2 Status Factor. Second Language Research, 27: 59-82.

Foote, R. (2009). Transfer and L3 acquisition: The role of typology. In Y.-k. I. Leung (Ed.), Third Language Acquisition and Universal Grammar (pp. 89-114). Clevedon: Multilingual Matters.

Flynn, S., Foley, C., \& Vinnitskaya, I. (2004). The Cumulative- Enhancement Model for language acquisition: Comparing adults' and children's patterns of development in first, second and third language acquisition of relative clauses. The International Journal of Multilingualism, 1, 3-16.

Hermas, A. (2010). Language acquisition as computational resetting: verb movement in L3 initial state. International Journal of Multilingualism 7(4). 343-362. http://doi.org/10.1080/14790718.2010.487941

Hermas, A. (2014a). Multilingual transfer: L1 morphosyntax in L3 English. International Journal of Language Studies, 8(2): 10-24.

Hermas, A. (2014b). Restrictive relatives in L3 English: L1 transfer and ultimate attainment convergence. International Journal of Multilingualism 34(3). 361-387. http://doi.org/10.1080/07268602.2014.898227

Huang, C.-T. J. (1984). On the distribution and reference of empty pronouns. Linguistic Inquiry, 15, 531-74.

Ionin, T., Zubizarreta, M. L. and Philippov, V. (2009). Acquisition of article semantics by child and adult L2English learners. Bilingualism: Language and Cognition, 12: 337-361.

Jaensch, C. (2009a). L3 acquisition of the German determiner phrase: The role of L1 Japanese and L2 English. Saarbrücken: VDM Verlag.

Jin, F. (2009). Third language acquisition of Norwegian objects: Interlanguage transfer or L1 influence? In Y-k. I. Leung (Ed.), Third Language Acquisition and Universal Grammar (pp. 144-161). Bristol, UK: Multilingual Matters.

Kornfilt, J. (1997). Turkish. London: Routledge.

Leung, Y.-K. I. (2005b). Second vs. third language acquisition of tense and agreement in French by Vietnamese monolinguals and Cantonese-English bilinguals. In J. Cohen; K. McAlister; K. Rolstad, \& J. MacSwan (Eds). ISB4: Proceedings of the 4th International Symposium on Bilingualism (pp. 1344-1352). Somerville, MA: Cascadilla Press.

Montrul, S., Dias, R., \& Santos, H. (2011). Clitics and object expression in the L3 acquisition of Brazilian Portuguese: Structural similarity matters for transfer. Second Language Research, 27: 21-58.

New, B \& Pallier, C. (2001). List of the 500 most frequently used French words,available at: (http://french.languagedaily.com/wordsandphrases/most-common-words. (accessed 10 April, 2016).

Puig-Mayenco, E, Alonso, G. J. \& Rothman, J. (2018). A systematic review of transfer studies in third language acquisition. Second Language Research 34(1). http://doi.org/10.1177/0267658318809147.

Rothman, J. (2011). L3 syntactic transfer selectivity and typological determinacy: The Typological Primacy Model. Second Language Research, 27: 107-127.

Rothman, J. (2013). Cognitive economy, non-redundancy and typological primacy in L3 acquisition: Evidence from initial stages of L3 Romance. In S. Baauw, F. Dirjkoningen \& M. Pinto (eds.), Romance languages and linguistic theory (pp. 217-247). Amsterdam: John Benjamins.

Rothman, J. (2015). Linguistic and cognitive motivations for the Typological Primacy Model (TPM) of third language (L3) transfer: Timing of acquisition and proficiency considered. Bilingualism, 18(2): 179-190.

Slabakova. R. (2016). The Scalpel Model of Third Language Acquisition. International Journal of Bilingualism, 115

Underhill, R. (1976). Turkish grammar. Cambridge, Mass: MIT Press.

Westergaard M, Mitrofanova N, Mykhaylyk R, et al. (2016). Crosslinguistic influence in the acquisition of a third language: The Linguistic Proximity Model. International Journal of Bilingualism, 1-17.

Yılmaz, G. (2006). L2 acquisition of the English article system by Turkish learners. Unpublished MA dissertation, Boğaziçi University, Istanbul. 